International Journal of Applied Mathematics

Volume 30 No. $3 \quad 2017,239-251$

ISSN: 1311-1728 (printed version); ISSN: 1314-8060 (on-line version)

doi: http://dx.doi.org/10.12732/ijam.v30i3.3

\title{
AN ANALYSIS OF THE DAILY VARIATION OF THE VALUE OF AN OPTION OF A SHARE THROUGH THE BLACK-SCHOLES EQUATION
}

\author{
Josiane Correia de Souza Carvalho ${ }^{1}$, Silvio Antonio Bueno Salgado ${ }^{2}$, \\ Marçal Serafin Cândido ${ }^{3}$, Reinaldo Marques ${ }^{4}$ \\ 1,2,3,4 Instituto de Ciências Sociais Aplicadas - ICSA \\ Universidade Federal de Alfenas UNIFAL - MG \\ Celina Ferreira Ottoni Avenue, 4000 - Padre Vitor \\ Varginha - MG, 37048-395, BRAZIL
}

\begin{abstract}
In this work we study the daily variation of an option through a mathematical model known as Black-Scholes equation. This model expresses the variation rate on the derivative price, regarding time, as a linear combination of three terms: the own derivative's price, the speed with which it varies regarding the share price, and how this variation is accelerated. The main goal is to analyze the theoretical model's approximation when applied to practice, for this is presented the Black-Scholes model's solution and posteriorly applied on a European call option. This allows us to come to the conclusion that the theoretical model presented itself is a fine approach with the market.
\end{abstract}

AMS Subject Classification: 91G80, 97M30

Key Words: mathematical finance, Black-Scholes equation, European options, derivatives, partial differential equations

\section{Introduction}

The Brazilian financial market is segmented into four major markets, among them the real state stock market, where stocks, debentures and investment fund shares are negotiated. During the last century, real estate stocks that

Received: April 3, 2017

(C) 2017 Academic Publications

${ }^{\S}$ Correspondence author 
earned more and more space in the economic dynamics are called derivatives, that basically are contracts for future settlement. The growth in the use of derivatives is due to the fact that uncertainties and operations monetary volume are increasingly large, making the agents to want to protect themselves more against the risk of losses.

A type of derivative that is being largely used on the market, especially for risk management, are called European call options. These contracts are priced, and being able to determine the option's ideal value is extremely important, because the European option's dynamics allows its commercialization on the secondary market, this way becoming useful for the agents to know the price of an option before its expiration due date. For this purpose, there is the BlackScholes model, describing how a derivatives price varies as time passes by, and is used to calculate the European call option's value.

The Black-Scholes model is cited as one of the seventeen equations that changed the world [7] and this mathematical model was a very important discovery that earned various awards to its developers, among them the Nobel Memorial Prize in Economics Sciences in 1998. The goal of this work is to analyze the value's daily variation throughout the Black-Scholes model to verify if the pricing by the model, approaching the indeed practical pricing on the market.

Initially, it was proved that the Black-Scholes equation is equivalent to a diffusion problem and so the Black-Scholes model presented a solution. Posteriorly, it was shown, using the principal of maximum, that such solution is unique. Then, the solution is programmed and five required parameters to calculate the call's value by the model are obtained so daily values by the model of Black-Scholes are compared with the daily values practiced by the market.

\subsection{Options}

The options market is one of the most flexible among the derivatives, and has an important role on recent developments of this financial instrument, once it allows several strategies to be done, focused mainly on price risk management. Options are a type of derivatives in which, through a previous payment, is acquired the right to buy or sell goods in a predetermined future value [5].

Therefore there are specific agents and own characteristics of this contractual type, and they have definite thermologies. The amount paid to acquire the option's right is called prize, the right exercise's right (in other words, the future value agreed), is determined as strike, the agent that assumes the risk is the launcher and who obtains the right is called holder, [2]. 
As quoted, the contracts can provide the right to buy or to sell some asset in future date. Also depending on the operation that is going to be done the contract is classified in: call options or put options. To classify the contract, an analysis should be made on which right is being agreed. If the option's holder obtains the right to buy, the contract is named call option; if the right is acquired to be sold, it is a put option [5].

Besides these classifications, there are two styles of options: American and European. These are related to the contracts exercise's date. On an American option the holder can exercise his right at any time, since the purchase date until its due date.

The name's origins are derived from the past practices on American stock exchanges (Chicago), and the European (London), however, currently both options are present on several countries, and do not have geographical references but, exclusively, to the contract's exercise date [5]. Hence, European call options are the ones in which the holder secures the right to buy an asset on a determined future date, and the call options are those in which the holder secure the right to buy an asset and can exercise this right until the future determined date. It is worth to reinforce that the options can or cannot be exercised, after the due date they cease to exist.

One difficulty that remained for a long time was how to establish the prize amount to be paid to the launcher, once each sort of asset had specifications that made it difficult to deduce the amount to be paid for the launcher to assume the risk, and this was one question of questionable answers during a long time. In 1973 it was introduced a mathematical model described as Black-Scholes equation, that showed itself capable to purpose the prize amount, [2]. There are other ways to calculate the prize amount, as for example, the binomial model, however on this paper is used the Black-Scholes model.

\subsection{Black-Scholes Equation}

Risks are naturally present on everyday life, and to self protect against the burden and it's attractive to financial agents, mainly on this market where one of the rules, if you want to gain money you should take risks. Regardless of all, these risks can cause devastating losses, thus the idea of getting rid of them is something fascinating, but seen by much as an utopic idea.

When operations with options appear, that permit the agent to use just the favorable consequence of the contract, it was noticed that the options were capable, somehow, to eliminate the risks, [7].

As showed previously, these contracts have an initial amount, the prize, and 
how to price options was a big challenge on de 1960's, and during many decades academics have tried to develop a mathematical model capable to price options, but researches about factors that influenced the pricing ended by introducing a few symbols that made the goal to be even further, [7].

As until 1955, the mathematicians Fisher Black and Myron Scholes, defined only five variables capable to tell the options value: the share price, its volatility, the contract's duration, interest rate and risk level. Eliminating several symbols was enough to demonstrate these five variables and this step made the mathematical model the most probable resolution, see [5].

All variables defined by Black and Scholes were measurable, except the risk. So they thought in a way to make the risk insignificant. The way they found was to bet on the stock market in opposite directions, known as dynamic hedging. With this strategy they were able to create a fully risk free stock portfolio, and so, with the other variables being measurable, it was possible to price an option, [2].

This discovery was fantastic, however there was a problem. It took time to compute the dynamic hedging, the markets move fast, therefore the calculations were outdated. It was necessary a way to measure the risk in a continuous shape instantly, and this problem was resolved by Bob Merton, in which he used an unknown tool by Fisher Black and Myron Scholes: the Itô calculus, making the equations an elegant mathematical model that utilized partial differential equations [2].

The development of an equation was able to eliminate the risk and to price the option's contracts was and this discovery was revolutionary, and the model was used on several financial markets obtaining satisfactory results. In 1973 Fisher and Scholes presented a formula in an article and it was immensely cited by many other writers, the recognition by its developers were diverse, from financial gains to innumerous prizes, including in 1997 Merton and Scholes received the Nobel Memorial Prize in Economics Sciences, in which time Fisher had already passed away.

The Black-Scholes equation is given by:

$$
\frac{\partial C}{\partial t}+\frac{1}{2} \sigma^{2} S^{2} \frac{\partial^{2} C}{\partial S^{2}}+r S \frac{\partial C}{\partial S}-r C=0
$$

It shows the five variables: time $t$, asset's price $S$, the derivative's price $C$, the risk free interest rate $r$ and the share's volatility $\sigma^{2}$. This formula expresses the derivative's price variation rate, related to the time, as a linear combination of three terms: the price of the own derivative, how fast it varies in relation to the share's price and how this variation is accelerated. If the terms that 
represent the price of the derivative and its variation rate were omitted the equation would be exactly like the heat equation. In 1973 Black and Scholes [2] delineated the model's assumptions, which are the next:

1. The long-term interest rate is known.

2. The price of the asset follow a continuous random way and has long-term distribution.

3. The asset does not pay dividends or others distributions.

4. The European option can only be applied in its maturity.

5. There is no transition cost on share and option's purchase or sale.

6. It is possible to invest any fraction of assets or derivative on fully free risk rate.

7. There are no penalties on short-selling operations, that is, short sale.

Stewart (2013), emphasizes on his book that the Black-Scholes equation was deduced using several simplifying financial assumptions. It presupposes that the market prices behaves statistically with Brownian movement ${ }^{1}$, thus the Black-Scholes equation was elaborated to propitiate in rationality level to future markets, and also to provide the value of an option before its matures, which effectively does on normal market's conditions. It is worth pointing out the initial assumptions were lazy on later works.

\section{Transformation of the Black-Scholes Model into a Diffusion Problem}

On the Brazilian market is more common the European call options to be used. The Black-Scholes equation, to price one European call described as $C$, depending on the underlying asset's value defined on the equations as $S$, so as time $t$ e the strike value $K$, this way $C$ is in function of $S$ and $t$. With this,

\footnotetext{
${ }^{1}$ The term Brownian movement is used to refer to a mathematical model utilized to describe random movements, which sometimes is called the particle theory.
} 
Black-Scholes model will be given by:

$$
\left\{\begin{array}{l}
\frac{\partial C}{\partial t}+\frac{1}{2} \sigma^{2} S^{2} \frac{\partial^{2} C}{\partial S^{2}}+r S \frac{\partial C}{\partial S}-r C=0 \quad \text { in } \Omega \\
C(S, t)=\max \{S-K, 0\} \\
C(0, t)=0 \\
\frac{C(S, t)}{S} \rightarrow 1, \text { when } S \rightarrow+\infty,
\end{array}\right.
$$

$\Omega=\{(S, t) ; S>0$ and $0<t<T\}$.

Throughout the changes on the fitting variables, the Black-Scholes model is equivalent to a diffusion problem. According to the variables changes [8]:

$$
\left\{\begin{array}{l}
S=K e^{X} \\
t=T-\frac{\tau}{\frac{1}{2} \sigma^{2}} \\
k_{1}=\frac{r}{\frac{1}{2} \sigma^{2}} \\
v(x, \tau)=e^{\alpha x+\beta \tau} u(x, \tau),
\end{array}\right.
$$

on what $\alpha=-\frac{1}{2}\left(k_{1}-1\right)$ and $\beta=-\frac{1}{4}\left(k_{1}+1\right)^{2}$.

Theorem 1. With the variables changes as in (3), the Black-Scholes model for an European call is corresponding to the Cauchy problem for the diffusion equation:

$$
\begin{gathered}
\frac{\partial u}{\partial t}=\frac{\partial^{2} u}{\partial \tau^{2}}, u(x, 0)=u_{0}(x), \quad x \in \mathbf{R}, \\
u(x, 0)=u_{0}(x)=\left\{\begin{array}{ccc}
e^{\frac{1}{2}\left(k_{1}+1\right) x}-e^{\frac{1}{2}\left(k_{1}-1\right) x} & \text { if } & x \geq 0 \\
0 & \text { if } & x<0
\end{array},\right. \\
\left\{\begin{array}{l}
\lim _{x \rightarrow-\infty}\left(e^{-\frac{1}{2}\left(k_{1}-1\right) x-\frac{1}{4}\left(k_{1}+1\right)^{2} \tau} \cdot u(x, \tau)\right)=0 \\
\lim _{x \rightarrow+\infty} \frac{u(x, \tau)}{e^{\frac{1}{2}\left(k_{1}+1\right) x+\frac{1}{4}(k+1)^{2} \tau}}=1
\end{array}\right.
\end{gathered}
$$

Proof. See [3].

Definition 2. The function

$$
K(x, t)=\frac{1}{\sqrt{4 \pi t}} \exp \left(-\frac{x^{2}}{4 t}\right), \quad x \in \mathbf{R}, t>0
$$

is called heat core. 
Theorem 3. Let $F \in C(\mathbf{R})$ be limited. Then the function

$$
u(x, t)=\left\{\begin{array}{l}
\int_{-\infty}^{+\infty} F(y) K(x-y, t) d y, \quad x \in \mathbf{R}, t>0, \\
F(x), \quad x \in \mathbf{R}, \quad t=0
\end{array}\right.
$$

is the solution to the diffusion problem

$$
\left\{\begin{array}{l}
\frac{\partial u}{\partial t}=\frac{\partial^{2} u}{\partial x^{2}}, \quad(x, t) \in \mathbf{R} \times(0,+\infty) \\
u(x, 0)=F(x), \quad x \in \mathbf{R} \\
u \in C^{2}(\mathbf{R} \times(0,+\infty)) \cap C(\mathbf{R} \times[0,+\infty)) \\
u \text { limited }
\end{array} .\right.
$$

Proof. See [6].

We use Theorem 5 and come back to the original variables:

$$
\left\{\begin{array}{l}
x=\ln \left(\frac{S}{K}\right) \\
\tau=\frac{1}{2} \sigma^{2}(T-t) \\
v=\frac{C(S, t)}{K} \\
k_{1} \tau=r(T-t)
\end{array} .\right.
$$

The call value is given by

$$
C(S, t)=S \cdot N\left(q_{1}\right)-K \cdot e^{-\tau(T-t)} N\left(q_{2}\right),
$$

in which

$$
N(y)=\frac{1}{\sqrt{2 \pi}} \int_{-\infty}^{y} e^{-\frac{1}{2} q^{2}} d q,
$$

and $q_{1}$ and $q_{2}$ can be expressed directly in $S$ and $t$

$$
\begin{aligned}
& q_{1}=\frac{\ln (S / K)+\left(r+\frac{1}{2} \sigma^{2}\right)(T-t)}{\sigma \sqrt{T-t}}, \\
& q_{2}=\frac{\ln (S / K)+\left(r-\frac{1}{2} \sigma^{2}\right)(T-t)}{\sigma \sqrt{T-t}} .
\end{aligned}
$$

The expression (6) is known as Black-Scholes formula, [3].

Theorem 4. The solution of the Black-Scholes equation, known as the Black-Scholes, is unique. 
Proof. Let us suppose there are two distinct solutions for the Black-Scholes denoted as $C(S, t)$ and $C^{\prime}(S, t)$. We define $W(S, t):=C(S, t)-C^{\prime}(S, t)$. So the function $W(S, t)$ satisfies the Black-Scholes equation and

$$
\left\{\begin{array}{l}
W(S, t)=0 \\
W(0, t)=0 \\
W(S, t) \longrightarrow 1 \text { when } S \longrightarrow+\infty
\end{array}\right.
$$

because the convergence $W(S, t) \longrightarrow 1$ is uniform and $0 \leq t \leq T$. By the maximum principle, we have

$$
|W(S, t)| \leq c S, \quad S \geq 0, \quad 0 \leq t \leq T
$$

The variable $c$ is independent from $S$ and $t$. Now using the function $u$, we have

$$
u(x, \tau)=\frac{1}{E} \exp -\alpha x-\beta \tau W(S, t)
$$

$S=E e^{x}, t=T-\frac{2 \tau}{\sigma^{2}}$. So

$$
|u(x, \tau)| \leq M e^{a|x|}, \quad x \in \mathbf{R}
$$

with $M$ and $a$ positive constants. So the solution is for this equation $u_{\tau}=u_{x x}$, $x \in \mathbf{R}$ and $0<\tau<\frac{\sigma^{2} T}{2}$. The initial condition $u(x, 0)=0$ is only determined by the classes of functions satisfying condition $(7), u(x, \tau)=0$.

\section{Application}

The goal is to use the Black-Scholes equation, to analyze the daily variation of a European call option's price of a share, and compare, if the foreseen values by the model approximate of what is really done on the market.

\subsection{Application's Methodology}

By means of Microsoft Visual Basic for application - VBA, which is a tool from Excel, the Black-Scholes equation was found, programmed [1], and after this, it was possible to find the value of and European call option for a share.

By its relevant role on the Brazilian stock market it was decided to follow a call option from Petrobras, in March 2016 the company's shared made $\mathrm{R} \$ 212$ 
million circulate on Bovespa. This is $8,5 \%$ from to amount negotiated on Brazilian stock exchanges that month (Bovespa). To calculate the daily value of the option by the model is necessary five parameters. Next, it will be presented from where the data from which each one was taken.

The values for the underlying asset $(S)$ were taken from Yahoo Finance website $^{2}$, that has an option called Historical Prices, and by this is possible to follow the share's value of the company, on weekdays. The strike value $(K)$ was also taken from Yahoo Finance, in which, on the Option section was chosen the strike's contract of $\mathrm{R} \$ 6,50$.

The time was calculated using a simple subtraction of the option final date by the desired date to determine the option's value. The risk free interest rate $(r)$ was the Selic rate, converted to days ${ }^{3}$, because the analysis was made using the period of one day as base.

The volatility value is the most complicated parameter to be determined, as cited previously. On researches are found two types of volatility, the explicit and the implicit volatility.

The explicit volatility is a measure by the standard deviation of the asset's price, and implicit volatility is calculated, to satisfy the Black-Scholes equation, by putting the obtained call values and with this is determined the necessary value of the volatility to fulfill the equation. It was chosen to use the explicit volatility because the objective is to examine the model approximation. Therefore, using as base on Benninga (2000) to calculate the value of $\sigma$ became the base to historical returns of the underlying asset.

\subsection{Application's Development}

Initially the Black-Scholes formula was programmed on VBA, so it was possible to calculate and do the desired comparisons, it is showed on Figure 1 how the programming was made.

After one call option from Petrobras was selected, the strike on $\mathrm{R} \$ 6,50$ with a due date on $06 / 17 / 2016$. Initially were obtained data referring to the underlying asset's value, time, risk free interest rate and volatility by historical returns, and so, it was possible to calculate the European call option, as exposed on Table 1, which obtains all five parameters and the calculated value by the model according to the programmed formula. It is worthy to emphasize that $S$ - underlying asset's value, $X$ - strike's value, $t$ - time, $r$ - risk free interest rate and $\sigma$ - volatility.

\footnotetext{
${ }^{2}$ http://https://br.financas.yahoo.com/

${ }^{3}$ Data taken from federal revenue
} 


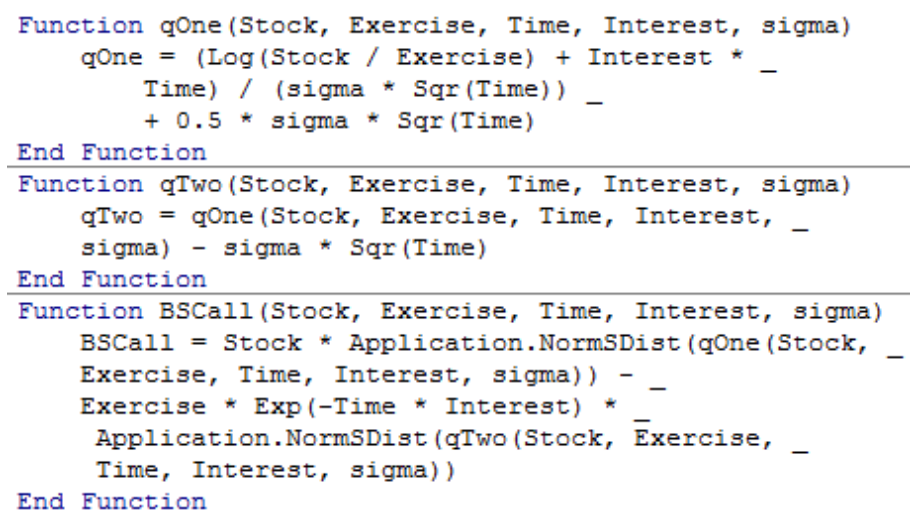

Figure 1: Programming on VBA of the solution of the Black-Scholes equation for a European call.

\begin{tabular}{ccccccc}
\hline Data & $\mathrm{S}$ & $\mathrm{K}$ & $\mathrm{t}$ & $\mathrm{r}$ & $\sigma$ & Call price \\
\hline $23 / 05 / 2016$ & 6,15 & 6,50 & 25 & 0,000367 & 0,049824451 & $\mathrm{R} \$ 0,49$ \\
$24 / 05 / 2016$ & 6,18 & 6,50 & 24 & 0,000367 & 0,04942408 & $\mathrm{R} \$ 0,49$ \\
$25 / 05 / 2016$ & 6,19 & 6,50 & 23 & 0,000367 & 0,049039344 & $\mathrm{R} \$ 0,47$ \\
$\vdots$ & $\vdots$ & $\vdots$ & $\vdots$ & $\vdots$ & $\vdots$ & $\vdots$ \\
$14 / 06 / 2016$ & 6,02 & 6,50 & 3 & 0,000367 & 0,048490928 & $\mathrm{R} \$ 0,05$ \\
$15 / 06 / 2016$ & 6,17 & 6,50 & 2 & 0,000367 & 0,048215636 & $\mathrm{R} \$ 0,06$ \\
$16 / 06 / 2016$ & 6,22 & 6,50 & 1 & 0,000367 & 0,047905631 & $\mathrm{R} \$ 0,03$ \\
\hline
\end{tabular}

Table 1: Parameters of the option of Petrobras: value of the asset, exercise's price value, remaining time until the due date, Selic, volatility and call prices calculated by Black-Scholes.

Figure 2 shows graphically the values that were calculated by the model comparing with the values that were indeed used on the market. With an appropriate approximation, we can conclude that the theoretical model on practice has a good application and opens the door to discussions about its use on the stock market to manage risk and profit.

Figure 2 demonstrates that the theoretical model holds a good approximation with what was used on the market, since the correlation coefficient between the calculated data by the model and the values, indeed practiced on the market, was 0,96 . This way, the aim is to verify the applicability of the theoretical model on practice can be analyzed on the following manner, with the methodol- 


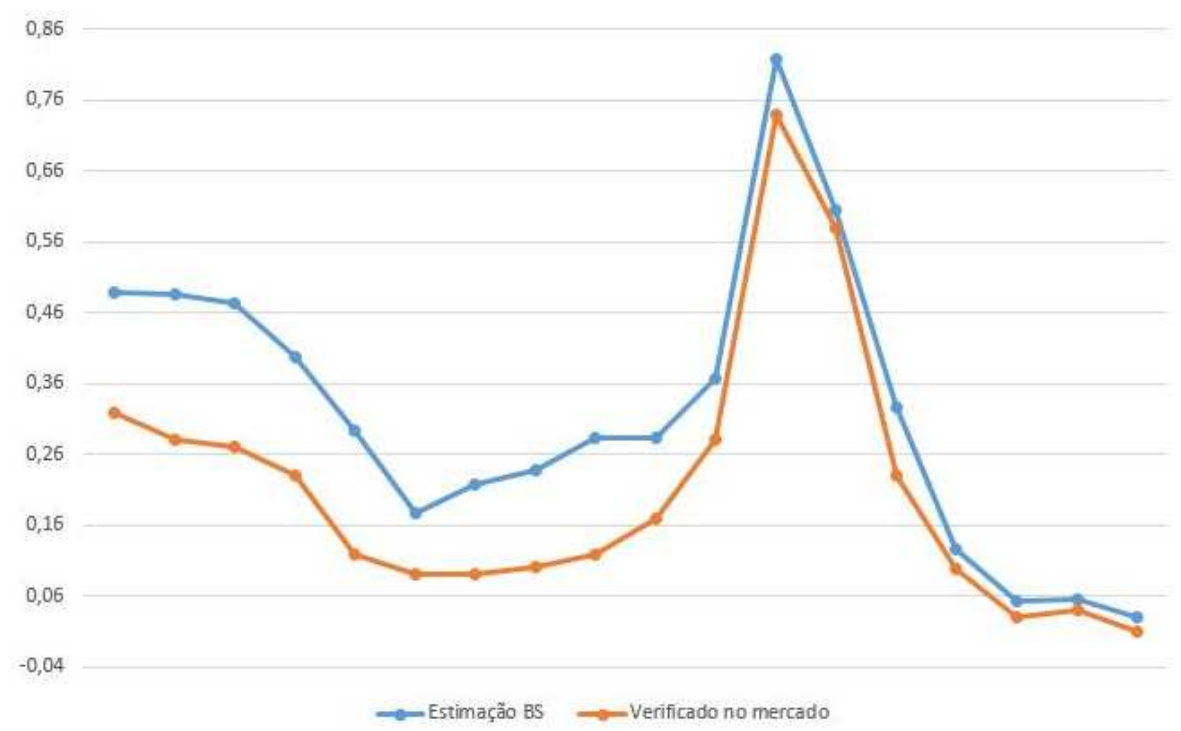

Figure 2: Call values from Petrobras calculated by Black-Scholes and seen on the market, $\mathrm{x}$-axis - time from $05 / 23 / 2016$ to 06/16/2016, $\mathrm{y}$-axis - call values in reais.

ogy applied and for the analyzed call option, the pricing model was acceptable when compared with the practical results. bigskip

\section{Final Remarks}

The Black-Scholes equation is a sophisticated model with partial differential equations of second order that, using changes on variables and partial differential equations' techniques, can be changed on the heat equation. The main advantage of using this model is acquire in the end an exact solution, for that reason when finding a solution was possible to obtain one simpler version to program and use of the Black-Scholes model.

The model's application aims to analyze the pricing an European call option from Petrobras presented values, when compared, they approximated to the values that were indeed practiced on the market. Once the pricing made by the Black-Scholes equation is not the only one use for options, the importance of these results is to obtain a good approximation that the theoretical model of Black-Scholes possess what is really done.

Although satisfactory, the results obtained have some limitations, for ex- 
ample, the method used to guess the share's volatility is not unique on the mathematical literature, another method that can be efficient in other situations. Using this method is just an option. To calculate thee call's value using the Black-Scholes formula is necessary the asset's value so, we perceive that there is one approximation, but being forced to wait the share's daily value, the prediction just covers on a short time.

What could be done to solve this problem is utilize one predicting method to future price the asset, however is this estimation of one of the parameters can also be efficient the use of methodologies that deal with uncertainties, as for example, the Fuzzy logic, becoming possible the option s future pricing. Besides the application on other assets, looking forward to a high quality ground on conclusions made about this model.

Once several companies, including insurers, use financial market's products to acquire necessary income and supply future debts, attempts to model and to understand the operation of the option's market is extremely important in the actuarial sector, because this segment can be used on risk manage and as hedge strategy. Besides other applications, since the option's contract can be utilized to price an insurance contract and to evaluate financial assets, as well as the evaluation of the insurance company by option's theory.

\section{References}

[1] S. Benninga, B. Czaczes, Financial Modeling, MIT Press (2000).

[2] F. Black, M. Scholes, The princing of options and corporate liabilities, The Journal of Political Economy, 73 (1973), 637-654.

[3] M.R. Grossinho, Métodos numéricos em finanças. ISEG (2009).

[4] M. Horn, Explain the concept of implicit volatility and how it measured, in the context of options prices, outline, and critically assess, the uses that can be made of implicity volatility, EC 372 Term Paper, Department of Economics, University of Essex (2009).

[5] J.C. Hull, Options, Futures, and Other Derivative. Pearson Education India (2006).

[6] V.M. Iório, EDP: Um curso de graduação. Instituto de Matemática Pura e Aplicada (1989). 
[7] I. Stewart, Dezessete equações que mudaram o mundo, Zahar (2013).

[8] P. Wilmott, S. Howison, J. Dewynne, The Mathematics of Financial Derivatives: A Student Introduction. Cambridge University Press (1995). 
